\title{
Giving answers or raising questions?: the problematic role of institutional ethics committees
}

Janet E Fleetwood, Robert M Arnold and Richard J Baron The Medical College of Pennsylvania, University of Pittsburgh, and the Medical College of Pennsylvania respectively

\section{Authors' abstract}

Institutional ethics committees (IECs) are part of a growing phenomenon in the American health care system. Although a major force driving hospitals to establish IECs is the desire to resolve difficult clinical dilemmas in a quick and systematic way, in this paper we argue that such a goal is naive and, to some extent, misguided. We assess the growing trend of these committees, analyse the theoretical assumptions underlying their establishment, and evaluate their strengths and shortcomings. We show how the 'medical consultation' model is often inappropriately applied to IECs and suggest that IECs must operate under a different framework. Finally, we argue that IECs should be valued for the process they facilitate, and not for the product that they are, often unreasonably, expected to deliver.

Despite a stampede of enthusiasm, the broad acceptance of institutional ethics committees (IECs) in American health care represents only a veneer of consensus covering profound confusion regarding IECs' mission. Although a major force driving hospitals to establish IECs is the desire to resolve painful clinical dilemmas in a quick and systematic way, in this paper we argue that such a goal is naive and, to some extent, misguided.

We first describe the origin of IECs and the sociocultural forces that led to their development, explaining how conflicting forces have produced confusion and ambivalence about IEC goals. In section II we argue that IECs' primary value is in their ability to promote a pluralistic exchange of values. We urge readers not to accept the 'medical consultant' model for IECs, which creates the expectation that they will simplify complex clinical decision-making, but to recognise instead that by emphasising the ethical implications of clinical care IECs may complicate individual clinical decisions. In section III we discuss IEC composition and activities, including education, policy recommendation, and case review. We elucidate many of the potential pitfalls confronting IECs,

\section{Key words}

Medical ethics; institutional ethics committees; multidisciplinary hospital committees. including the psychological realities of legalism and bureaucratic inertia. Finally, we suggest that carefut attention be paid to the organisation, composition, andw rules governing IECs' operation to ensure an open discussion of ethical issues. We argue that only rigorous efforts to harmonise IECs' processes with IECs' goals will achieve congruence and fidelity in the work of ethics committees. \section{The origin of institutional ethics committees Three major American events are credited for the} burgeoning interest in IECs. First, in 1976 the New Jersey Supreme Court recommended using an 'ethge \$5 committee' to confirm the prognosis of a comatese woman, Karen Ann Quinlan, whose family requese termination of life support (1). While subsequent IE concentrated on ethical issues rather than validatings medical prognoses, this was the first case in the Uniteô States in which the court suggested committe decision-making in what had previously been the private province of doctors and patients. It is significant that the first appeal to an 'ethics committee' was to resolve purely medical, rather than ethicalop. questions, and we believe that this foreshadowed of persistent confusion about IEC goals.

In 1983, ethics committees were given additiona: validation by the President's Commission for the Study of Ethical Problems in Medicine and Biomedical an $\$$ Behavioral Research, when the commission urged health care professionals and administrators to develop? mechanisms for review and consultation in casess raising ethical issues. Specifically, the commission. suggested ethics committees as a mechanism for resolving conflicts (2).

Finally, in response to the non-treatment of Down's syndrome baby in Indiana, the United States Department of Health and Human Services issued 'Infant Doe' regulations which strongly encourage hospitals to establish 'Infant Care Review' committeess (3).

Since the days of the Quinlan case, institutionalO ethics committees have represented a growing American and international phenomenon. While ir 1982 only one per cent of American hospitals had suck committees, by 1987, that figure had reached 60 pep cent (4). A variety of influential medical groups, 
including the American Medical Association, the American Hospital Association, the American Academy of Pediatrics, and the American Academy of Neurologists has endorsed IECs (5), and experts expect them to play an increasing role in the medical setting (6).

It is important to understand IECs' increasing prevalence in the context of broad cultural changes that occurred over the last three decades. The American civil rights movement, the concern for consumer protection, and public hearings involving government officials are but a few examples of Americans' increasing willingness to challenge authority. This change in attitude strongly influenced both physicians' role in society and their relationship with individual patients. Heightened media exposure and the growing public fascination with new medical technology brought an increasing sense that physicians were unilaterally making decisions that were as much moral as medical. The 1970 s and 1980 s marked a gradual shift in public attitude towards medicine from one of uncritical acceptance to considerable suspicion (7).

One way to offset physicians' power and biases in problematic cases is to refer decision-making to a pluralistic group. In American society, the jury embodies the quintessentially democratic committee. Greater numbers of medical malpractice lawsuits are one indication of the growing dissatisfaction with physicians' unilateral clinical choices and the attempt to have a jury remedy the problem. However, the judicial process has limited value in handling bioethical conflicts, such as withholding life-sustaining treatment or allocating scarce medical resources. First, legal services are expensive, and the judicial system's bureaucratic, adversarial approach is not designed to address humanely the emotional issues faced by patients and health care professionals struggling with life-threatening issues. Second, the legal system often is not responsive to the time pressures of ethical conflicts in medicine. Court decisions are frequently announced months after the patient has either died or left the hospital. Finally, retrospective court judgements do not fulfill health professionals' need for hospital policies to help resolve ethical problems before they reach an impasse.

Many physicians, hospital attorneys, and administrators thought institutional ethics committees would be a compromise between the best attributes of physicians and the courts. Like physicians, IECs can respond comparatively quickly to requests for help. Like courts, IECs can rely on democratic processes and relatively consistent procedures for decision-making. In short, IECs are viewed as responsive forums in which diverse views are expressed, critically analysed, and ideally, reconciled, while avoiding insensitive, expensive, time-consuming litigation.

Thus many people look to institutional ethics committees to simplify the already complicated world of clinical medicine rather than to complicate it further by including various viewpoints. They want the committee to serve as a combination jury and ethics consultant, providing solutions to complex problems. Many physicians, nurses, administrators, and attorneys have turned to IECs because they seek 'right answers' and want an 'ethics consultant' to tell them what to do.

\section{The IEC as an 'ethics consultant'}

There are many parallels between the role physicians, and others, wish IECs would assume and the role accepted by medical subspecialists who function as consultants. The physician turns to a consultant for many reasons: confirmation of a clinical judgement, information regarding a disease or therapeutic regimen, or diagnostic recommendations for a clinical problem which is outside the referring physician's expertise. Physicians may request a cardiology consultation for help in treating a patient with refractory angina and thyrotoxicosis; similarly, a physician may seek an 'ethics consultation' in determining whether to uphold a patient's refusal of life-sustaining treatment (8). In essence, physicians see the consultant as the 'expert' with the authority to make recommendations regarding appropriate therapy. Medical specialists, in turn, are taught to give short specific suggestions, to identify the critical recommendations, and to be definitive in order to maximise 'compliance' of the referring physician and patient.

Ethics committees are often perceived on the medical consultant model. Since following the advice of the medical subspecialty expert, such as the cardiologist, usually leads to good results, it is understandable that health care professionals turn to ethics committees with the same expectations. They want those with the 'authority' and 'expertise' to offer short, definitive recommendations. However, we believe that this model, whether or not it is appropriate in the medical treatment setting, should not be adopted by institutional ethics committees.

Forcing ethics committees into the medical consultation model must be resisted, as it puts them in a untenable position. As a multidisciplinary committee in which 'authority' and 'expertise' are ill-defined, IECs are not suited to provide speedy 'right answers'. The different IEC constituencies have different, seemingly irreconcilable, ideas. Is the 'right answer' one that is most justifiable by Kantian ethics, by a utilitarian calculus, or by concerns about hospital liability or public image? Moreover, in a pluralistic society there is often disagreement about basic ethical issues, such as the definition of 'beneficence', the importance of applying principles or assessing consequences in ethical analysis, and the role that religious concerns should play. The cases with the most moral perplexities are likely to be the cases coming before the committee, and are themselves the very cases which are open to many competing interpretations.

What is important in ethical reasoning is the process 
used to arrive at one's conclusions, and it is in this process that IECs have a useful role. Enriching the traditional biomedical viewpoint by exposure to the diversity of viewpoints present in an IEC may increase physicians' awareness of the ethical issues at stake and help a physician to analyse critically the justification of various alternatives. Biases are revealed, neglected values articulated, and novel solutions explored. In a pluralistic society the process of identifying values, analysing assumptions, and assessing the justification of options is thought to lead to better decisions, and it is this process which IECs can help implement.

Rather than promising more than they can deliver, rather than moulding themselves to fit an unsuitable medical consultation model, ethics committees should be circumspect in understanding their limits as well as their strengths. A new model, unique to IECs, is needed. While IECs are limited in their ability to provide speedy 'right answers', their clearest strength is their ability to facilitate the process of rational decision-making.

\section{Committee composition}

Perhaps the first challenge facing every IEC is determining its membership. If the committee were designed only to ensure hospital-wide consensus, then a multidisciplinary committee of hospital employees would be best. In contrast, a preponderance of hospital administrators, legal counsel, or risk managers would be appropriate if the committee's primary goal were to decrease institutional liability.

We argue that there are several reasons for believing that a broadly constituted ethics committee, including a wide spectrum of health care professionals as well as lay members, is most likely to facilitate a democratic process of analysis. Multidisciplinary committees may be able to develop educational programmes that appeal to a variety of health professionals rather than narrowly concentrating on ethical issues faced by physicians. Similarly, hospital policies that take different health professionals' responsibilities into account are more likely to be taken seriously than those that do not. As the President's commission notes, an interdisciplinary membership can 'minimise the tendency to take the committee's task as essentially technical', can 'prevent ethics committees from becoming uncritically accepting of, or adverse to, the view of any one professional or social group', and can make many different perspectives available to those who seek the committee's guidance (9).

However, we are aware that, in practice, physicians are the largest group represented on IECs (10), and non-physician members are predominantly health professionals who, given their training, may assess medical problems or weigh risks and benefits quite differently from the general patient population. Even more striking is the members' social and educational homogeneity. While 'multidisciplinary' IECs may be designed to be pluralistic, their success at fulfilling this goal is limited to involving a variety of individuals from the upper echelons of the institution. If the notion of 'representative diversity' is taken seriously, committee members should be chosen from a wide pool of? applicants, including members of the surrounding community who will be the institution's future patients? (11).

Moreover a pluralistic committee membership does를 not ensure a pluralistic discussion of the issues. Sociaf scientists have found that small groups may avoid controversial issues, ignore minority objections to the group position, and reach closure prematurely to 5 achieve consensus (12). Compromise, when merely forthe sake of reaching a speedy decision, undercuts the् moral pluralism of the interdisciplinary group. If one of the IEC's roles is to ensure that health professionals understand the various options and their ethicalimplications, then compromise for its own sake minimises the potential benefits.

In addition, IEC members must be aware that professional roles influence interaction betweeng members. Members from different disciplines may come to IECs with vastly different expectations abouff the committee's goals. Lawyers, for example, maye want IECs to decrease their institution's legal liability迟 while hospital administrators may want IECs to decrease intrahospital friction. Further, social psychologists have documented that whether or not perspective is heard has more to do with the prestige्युo the person espousing the position than with the contegn of the view. As Joel Frader, $M D$, of the University $\$$. Pittsburgh Center for Medical Ethics notes: 'Clinicas department heads or chief executive officers do nog leave their bureaucratic authority behind them as the enter ethics committees. Their presence and power may inhibit free expression from subordinates of simply override dissent'. (Unpublished observations.

In this regard it may be helpful to compare IECs te their multidisciplinary 'next of kin', the Institutionat. Review Board (IRB). A 1981 study of multidisciplinary research ethics committees (IRBs) ino the United Kingdom showed that the attitude of some. health care professionals towards lay members was thas the "lay members "had no function", or were "merelऐ a window-dressing exercise"...'(13). Ethics committee members, like IRB members, may be likely to defer to the opinion of those who are felt to have the mose. expertise. Such findings lead us to question whether an IEC's recommendations will be based on justifiable ethical arguments rather than considerations of intragroup power.

There are currently no provisions for assuring that committee members do not pressure one another fos hasty decisions, examine and verify all of the relevan facts, avoid bias, or are able to overcome the stricture? of professional role stratification. It is probablyo unrealistic to expect IEC members to divorce themselves from their professional roles, but w\$ believe these tensions can be anticipated and mitigate $\bar{\phi}$ by the operating rules of the committee. The IE chairpersons may, for example, attempt to limit 
groupthink by explicitly asking for objections or appointing committee members to raise objections to the majority view (14). If the multidisciplinary nature of IECs is to enhance their consultative function, then care must be taken to ensure that an open analysis of the ethical issues is actively encouraged.

\section{IEC activities}

There are striking similarities in the activities of committees in different institutions (15). Typical areas of effort include, in increasing order of controversy, the creation of educational programmes, the review of institutional policies, and case consultation. It is the last that provokes the most dispute even as it appears to be the activity most ardently, if ambivalently and inarticulately, sought. We will describe this range of typical activities and point out some of the dilemmas facing IECs as they try to carry them out.

\section{Education}

Newly formed IECs perceive their first task as educating the committee members and, to a lesser extent, educating the wider hospital community. However, the interdisciplinary nature of IECs creates special educational stresses since some members will have been selected because they have a particular job in the hospital and others will have been chosen on the basis of their experience in analysing bioethical issues. Educational programmes that help IEC members develop competence in analysing ethical issues are thus difficult to develop in a way that is appropriate to both groups.

In addition if, as some social scientists claim, group dynamics inhibit open discussion of issues, then committees would do well to include training in communication skills as well as theoretical issues in bioethics. By discussing cases and current bioethics literature the committee members obtain a common frame of reference, develop group discussion skills, and gain familiarity with and respect for differing perspectives. While it is unreasonable to expect education to guarantee better decision-making or overcome the influence of group dynamics, it can at least be expected to clarify moral considerations and enhance the discussion of the various values and options present in clinical decisions.

Many IECs design educational programmes for the hospital at large to increase health professionals' awareness of the bioethical, rather than biomedical, questions that cause disagreements about patient care. Clearly this will not always be welcome; clinical decisions are easiest when they are made to appear straightforward, and the interjection of a new, unfamiliar frame of reference for discussion is likely to provoke hostility. But hospital education - preparing staff to be receptive to new, non-traditional ways of approaching clinical decisions - is an important endeavour for IECs. Thus both committee and hospital-wide education are important, but need to be designed carefully to maximise their impact.

\section{Policy review and recommendation}

Most IECs review or develop hospital policies. Many committees, for instance, have reviewed policies on withholding cardio-pulmonary resuscitation and some have developed policies regarding the limits of other life-sustaining treatments. Potential new areas for policy development include organ retrieval and transplantation, cost containment, and the issues surrounding AIDS. By clearly delineating important values and outlining elements of the decision-making process, policies and guidelines can help health professionals deal with difficult ethical issues and define the limits of acceptable moral behaviour (16).

Once again, however, IECs are not likely to find a warm reception for their policy revisions or recommendations. Almost by definition, IECgenerated policies are likely to be somewhat complex and bureaucratic. The very people that have demanded help in resolving difficult dilemmas often bridle at what they regard as unnecessary formalism and cumbersome process. This issue is particularly critical for IECs because the gold standard for evaluating the effectiveness of policies should be their effect on health professionals' behaviour. If, for example, an ethically justifiable policy regarding resuscitation is ignored by house staff, as is the case at several hospitals with which the authors are familiar, then the IEC has not achieved its goal. To be effective, IECs must extend their efforts beyond policy revision and take on a number of followup tasks: they must develop educational programmes to encourage compliance, monitor policies' effectiveness, and make appropriate adjustments to encourage ethical behaviour.

\section{Case review}

Case review is by far the most problematic IEC task, yet it is the one most consistently expected and demanded by health professionals in search of clear answers to complicated questions. While we have argued that IECs should resist the temptation to provide such answers, they nevertheless can serve many useful functions in the clinical setting. Ethics committees play an important role in patient care by discussing difficult ethical issues, helping frustrated health professionals analyse cases systematically, and suggesting options that may not have been considered. Further, they may play a preventative function. As Weiden points out: 'The very existence of ethics committees as a potential resource for resolving ethical dilemmas may defuse issues, thus preventing disagreements or misunderstandings from escalating' (17). Nevertheless crucial questions remain concerning the process of case review.

One obvious issue is determining who may bring cases before an IEC. Though many clinicians would like to have IECs as 'their' consultant which they bring in when they see fit, this view is overly narrow. If the goal of case review is to encourage a pluralistic consideration of ethical issues in patient care, as we advocate, then one must question many hospitals' 
custom of only allowing physicians access to the ethics committee (18). As Ross states in the American Hospital Association Handbook for Hospital Ethics Committees: 'It must be realised that one impetus to the formation of ethics committees was the belief of many hospital staff persons, especially nurses, that decisions were being made without sufficient consideration of ethical concerns. To restrict access to the ethics committee to physicians would certainly exacerbate those tensions even more' (19). Moreover, other health professionals, such as nurses, take their patient-advocacy role very seriously and may have much closer contact with patients than physicians. Bernard Lo has pointed out that these health professionals 'may raise previously overlooked issues, contribute new information or express the questions and viewpoint of patients and families' (20). The case for allowing patients and their families access to IEC review is even stronger, for it is the patient's health and values that are at stake, and these may not be adequately represented. Certainly patients need to be apprised of their option to request IEC involvement, and IECs should make an effort to assure this.

The strongest argument against ethics committees engaging in case consultation is that it may interfere with the doctor/patient relationship and lead to worse, not better, care. Physicians may be inclined to abdicate responsibility for patient decisions to a distant committee far from the bedside which is not responsible for the outcome. Avoiding this diffusion of responsibility will require that health care professionals, and courts, clearly understand that the committee's role is to broaden the decision-making process. The physician and patient remain ultimately responsible for health care decisions.

Concerns about responsibility for patient care warrant careful consideration however, and lead us to recommend evaluation of alternative methods for raising ethical issues in clinical practice. We must assess whether case review by an IEC is preferable to the work of an 'ethics consultant', whose sole responsibility is to make recommendations regarding morally difficult choices. This more closely follows the medical consultant model, although it fails to address our concerns about what it means to be an 'ethics expert'. Alternatively, we must decide whether it would be better simply to provide more extensive training to physicians to enable them to cope with moral decision-making within a pluralistic context. In our opinion, the answers to these questions, and thus the future role for IECs in case review, is unknown.

\section{Conclusion}

IECs now find themselves in a difficult dilemma: those swayed by the forces that were strongest in bringing IECs into being are those who are least patient with the complexities of the committee process. A kind of Faustian bargain has been struck: clinicians and administrators, searching for guidance and support in dealing with issues of ethics and liability, have created a fragile process that has trouble generating the kind of univocal solution that administrators and clinicians. most admire. In placing faith in process over outcome, hospitals must now be content with the awkwardness: of a pluralistic body which, by its very nature, makes decision-making more complicated precisely because iE includes more points of view. IECs must avoid being pressured into giving up their heterogeneity for the sake of prompt, definitive responses to the demandso imposed by those who may not fully recognise thes IEC's role. Hospitals, on the other hand, mus 5 understand that the creation of an IEC does not makeethical problems disappear; rather, it makes suchw problems less easy to dismiss or circumvent, and, in some sense, makes ethical problems even more्ठ difficult to resolve.

So, despite institutional pressures for quick, clear resolution of ethical dilemmas, merely resolving these problems is not the main work of an IEC. IECs should be valued for their process, if not their products, as? their major strength rests on their value as catalysts forthe examination of bioethical conflicts. While a simple coin toss would supply the speedy, unequivoca answers that many desire, IECs are obliged to confroni 3 all the ambivalence and uncertainty that made the decision difficult in the first place. This is the work and value of IECs.

\section{Acknowledgement}

We would like to thank Garrett Bergman MD, Cynthra Cohen PhD JD, Lachlan Forrow MD, Steve Martinō $M D$, and Sankey Williams MD for their thought provoking comments on earlier drafts of this paper.

Janet Fleetwood holds a PhD in philosophy from the University of Southern California and is an Assistane Professor at The Medical College of Pennsylvania in the. Department of Community and Preventive Medicine. She is Director of the Medical Humanities Program ando Regional Project Co-ordinator of the Delaware Valley Ethics Committee Network, a project of the Hastings. Center, The William Penn Foundation, and the College of Physicians of Philadelphia.

Robert M Arnold, MD recently completed a Robers Wood Fohnson Foundation Fellowship at the University of Pennsylvania and is currently an Assistant Professor of. Medicine in the Division of General Medicine at tho University of Pittsburgh. He is a general internist, the Director of Clinical Ethics Teaching, and holds a faculty appintment in the University of Pittsburgh Center for Medical Ethics. He has served on several hospital ethics committees, including those at the University of Pennsylvania and the Philadelphia Veteranss Administration Hospital.

Richard $\mathcal{F}$ Baron holds an MD degree from Yale University and is presently an Assistant Professor of Medicine in the Division of General Medicine at the? Medical College of Pennsylvania. He is chairperson of the institutional ethics committee there, and is a practising internist. 


\section{References}

(1) Veatch R. Hospital ethics committees: is there a role? The Hastings Center report 1977; 7:22-25.

(2) The President's Commission for the Study of Ethical Problems in Medicine and Biomedical and Behavioral Research. Deciding to forego life-sustaining treatment. Washington DC: US Government Printing Office, 1983:155-170.

(3) Levine C. Ethics committees: how are they doing? The Hastings Center report 1986; 3:9.

(4) Gibson J M, Kushner T K. Will the 'Conscience of an institution' become society's servant? The Hastings Center report 1986; 3:9-11.

(5) Cranford R E, Van Allen E J. The implications and applications of institutional ethics committees. Bulletin of the American College of Surgeons 1985; 70, 6:19-24.

(6) Anonymous. Who's for bioethics committees? [editorial]. Lancet 1986 May 3:1016.

(7) For a discussion of the change in public attitude towards the authority of the medical professional, see Starr P. The social transformation of American medicine. New York: Basic Books, 1984.

(8) Purtillo R B. Ethics consultations in the hospital. The New England journal of medicine 1984; 311, 15:983-986.

(9) See reference (2): 166

(10) See reference (2):450.
(11) Note that there is some question of breaching confidentiality by including lay members. For a general discussion of confidentiality see Cranford R, Hester F, Ashley B. Institutional ethics committees: issues of confidentiality and immunity. Law, medicine and health care $1985 ; 13,2: 52-60$.

(12) Lo B. Behind closed doors: promises and pitfalls of ethics committees [editorial]. The New England journal of medicine $1987 ; 317,1: 46-49$.

(13) Allen P A, Waters W E. Attitudes to research ethical committees. Fournal of medical ethics $1983 ; 9: 61-65$.

(14) See reference (12):48.

(15) Ross J W, Bayley C, Michel V, Pugh D. Handbook for hospital ethics committees. Chicago: American Hospital Publishing, Inc, 1986: 49-63.

(16) For example, a policy on resuscitation that requires a patient's consent prior to writing a 'Do Not Resuscitate' order tells physicians that patient participation in this decision is mandatory. For a further discussion of the role of policies in clinical care see Murray $\mathrm{T}$. Where are the ethics in ethics committees? The Hastings Center report $1988 ; 18,1: 12-13$.

(17) Weiden P. Ethics by committee? [editorial]. The New England journal of medicine 1987; 317, 22:1418.

(18) See reference (2):452.

(19) See reference (14):59.

(20) See reference (12):47.

\section{News and notes}

\section{Death and the brain}

There is now wide acceptance of the view that the irreversible loss of all brain function can be taken as a criterion of death. But this does not settle all arguments about death. Among the questions left open are: Is the use of brain death as a criterion of death a scientific decision or an ethical one? What implications does the use of the brain-death criterion have for our treatment of anencephalics, who are born with most or all of their brain missing? Does the use of the brain death criterion have any implications for the status of human embryos which have yet to develop a brain? Is there a sound basis for requiring the death of the whole brain, rather than "neocortical death" - that is, the death of those parts of the brain required for consciousness? Should we distinguish between the death of an organism and the death of a person? Can we contemplate the idea that a person has died while his or her body is still alive? If so, how should one treat such a body?

BIOETHICS invites contributions on any aspect of these issues, or on related ethical questions. Contributors who are in doubt about whether their topic will be suitable for the issue are invited to send us an outline of their work.

Submissions and/or enquiries should be sent to: Dr Helga Kuhse and Professor Peter Singer, Editors, Bioethics, Centre for Human Bioethics, Monash University, Clayton, Victoria, Australia 3168.

The deadline for submission of papers is January $15,1990$. 